\title{
APPLYING THE CONCEPT OF CIRCULAR ECONOMY TO INTEGRATED WASTE MANAGEMENT. CASE STUDY
}

\section{Diana Maria Ceapraz $^{1}$}

1 BDO Business Advisory, BDO Romania, 24 Invingatorilor St, 030922, Bucharest, Romania, diana.ceapraz@gmail.com

\begin{abstract}
Circular economy should define the new model for a sustainable environment and sustainable resource utilization. The traditional linear economy no longer supports the demands of an increasing population for new and better products. Reckless consumption threatens the viability of the current "take-make-dispose" model, and a shift in the mentality of both companies and customers is required, supported also by institutional and policy measures. Consumers will shift to users and producers and sellers will become service providers.

Long term benefits and opportunities of circular economy outweigh short term costs and threats, and all stakeholders should keep in mind that beyond fulfilling the needs for material consumption, there is a responsibility towards the environment. Design and innovation will play a key role for the transition to circular economy, and waste will no longer be considered as such, but as a valuable resource, while the emphasis will be on reuse, repair, reconditioning and recycling.

This paper assesses the potential of applying the concept of circular economy to integrated waste management, by analysing the available statistical data for Romania and European Union regarding waste management. The main improvement measures to apply are the implementation of a collection and sorting system partly funded through extended producer responsibility schemes, charging for waste generation, encouraging recycling, and transforming waste into energy instead of storing it in landfills. As the results show, a slight increase has been recorded for recycling rates in Romania and EU. However, there is place for improvement, and circular economy could represent the solution.
\end{abstract}

Key words: circular economy; integrated waste management; linear economy; recycling; waste generation.

\section{Introduction}

Circular economy is a generic term used for an industrial economy created on the intent to be restorative and in which material flows are of two types: biological flow, where processes act so as the components re-enter the biosphere safely, without negative effects, and the technical flow, where components are designed to circulate at high quality, without returning to biosphere [1].

Each year, in EU approximately 15 tonnes of materials per person are being used, and each EU citizen generates, on average, over 4.5 tonnes of waste per year, and half of it is discarded in landfills [2]. It becomes obvious that linear economy, based exclusively on resource extraction, is no longer a viable option.

The motivation of this paper resides in the necessity to identify an alternative to linear economy, in order to ensure environmental protection and natural resource sustainability. 
The objective of this paper is to highlight the potential of applying the circular economy concept to integrated waste management, by analysing the benefits and challenges of circular economy and also by assessing the current situation of waste management in EU and Romania.

The current linear model faces several challenges, and the results of Ellen MacArthur Foundation highlight the following aspects [3]:

- $\quad 3$ billion increase in number of middle-class consumers by 2030 , which will lead to higher rates of resource exploitation and higher prices for resources;

- Increased demand and increased raw materials supply risk;

- $\quad$ Decrease of corporate profits due to higher prices of resources;

- $\quad$ Reduced product lifespan, because of a positive feedback process;

- $\quad$ Decreased resistance of the current linear system (take-make-dispose model);

- $\quad$ Reduced recycling, recovery and reuse rates and an increased waste volume.

Circular economy represents the alternative to linear economy, since it ensures environmental protection and natural resources sustainability, by saving up to $70 \%$ of materials, compared to business-as-usual, by maintaining higher resource productivity and reducing long-term dependency on raw materials [4].

\section{What is Circular Economy?}

Several definitions were given for the term "Circular Economy". However, the concept cannot be traced back to one single date or attributed to one author. The idea dates back to 1970, and was known as regenerative design, while other concepts are performance economy, cradle-to-cradle, industrial ecology, biomimicry, green economy, blue economy, and natural capital. In brief, Circular Economy can be defined as [5]:

- An economic system which creates value based on use, not consumption, replacing the concept of "end of life" with restoration, and which has as starting point the reuse of products and materials and resource conservation;

- A zero waste concept, where products are designed and optimized for disassembly and reuse, and which preserves raw materials and products in productive circles as much as possible, and uses renewable energy. It is based on closing loops and expanding cycles (where possible, to infinity).

Design has a fundamental role in a circular economy. Companies should work with engineers to devise plans to design products and services which take into account the life cycle. Potential sectors for implementing circular economy are food and beverage, textile, packaging, waste, organic waste streams, metals and electronics, and "conflict" materials [6].

On 2 December 2015, European Commission adopted the Circular Economy Package, which includes the EU Action Plan for the Circular Economy. It will be funded through EU Structural and Investment Funds, namely Horizon 2020-the EU Research and Innovation Programme, and from Cohesion and Structural Funds for waste management. In the EU, circular economy can generate net savings of up to USD 630 billion and 100,000 - 200,000 new workplaces. Also, the 7th Environment Action Programme (EAP) will guide European environmental policy until 2020 [7].

What is Integrated Waste Management?

The general principles of waste management are gathered in the so-called "waste hierarchy", which sets out a priority order, from prevention, minimisation, reuse, recycling, and energy recovery to waste disposal. This principle encourages options 
which bring the best results regarding the environment [8]. Integrated waste management represents a reference framework for designing and implementing new waste management systems and for analysing and optimising existing systems. It is based on the fact that all (technical and non-technical) aspects of a waste management system should be considered together, because they are interconnected and the evolution of one area affects the practices or activities of another area [9].

Circular economy is based on the application of the 3 Rs reduce, reuse, recycle, thereby falling into the upper area of the waste hierarchy. The main difference between circular economy and integrated waste management is the fact that for circular economy, products are designed from the start for reuse.

\section{Materials and methods}

To assess the potential for transition to circular economy, and to analyse the evolution of waste management in Romania compared to EU, nine data sets with annual frequency, available on Eurostat [10] were used, regarding the structure of total waste generated (EU-28 and Romania), the recycling rate for municipal waste (EU-27 and Romania), recycling rate for waste packaging (total and by type of packaging), and recycling rate for e-waste. The total period analysed is from 2001 to 2014, with variations, depending on data availability. The results are presented in comparative graphs, showing the evolution for Romania and EU regarding waste management.

\section{Results and discussion}

Waste management plays a key role in circular economy, determining the way in which the waste hierarchy established by EU is implemented. According to Figure 3-1Error! eference source not found., mineral and solidified waste, which results from extraction (mining), construction and demolition

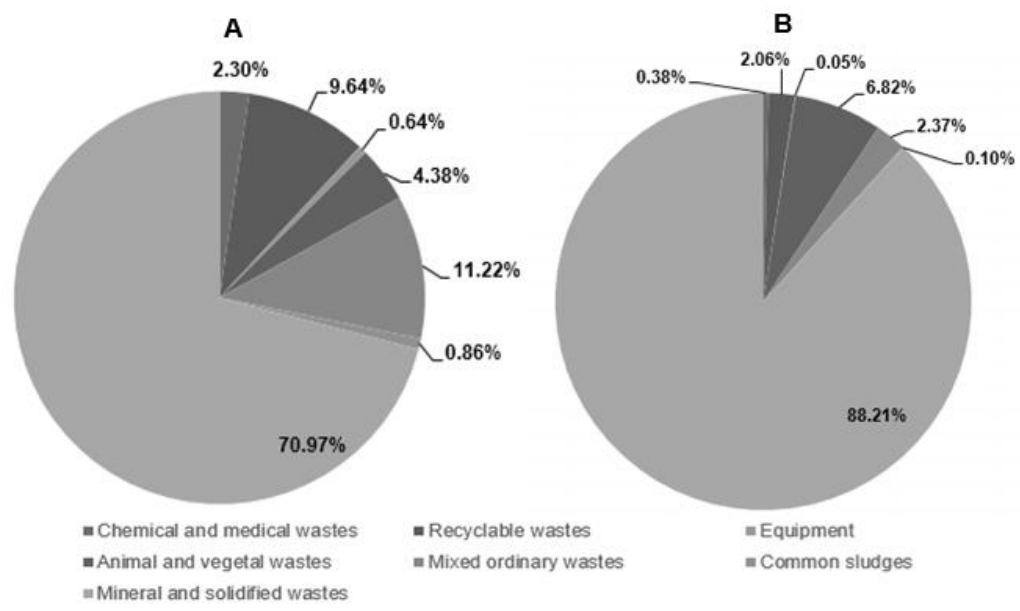

Figure 3-1. Structure of total waste generated in 2012 in EU-28 (A) and Romania (B)

activities, has the largest share both in EU and Romania. Mixed ordinary waste, which is mainly household waste, represents $11.22 \%$ for EU and $2.37 \%$ for Romania. The share of recyclable wastes is only $9.64 \%$ for EU and $2.06 \%$ for Romania. In absolute numbers, in 2012, EU produced 2,510,840,000 tonnes of waste, and Romania produced $266,975,602$ tonnes. Romania was ranked the third country in the EU, by total volume of waste generated in 2012, after Germany and France.

Figure 3-2 shows the evolution of municipal waste recycling rate for EU-27, Romania, Bulgaria and Hungary. The two neighbourhood countries were chosen in order to compare their evolution regarding recycling rate to that of Romania. As shown in the 
graph, recycling rates for the three countries are below EU-27 average, and Romania has the lowest rate, fortunately, on a positive trend since 2009.

Figure 3-3 presents the evolution of recycling rates for total packaging waste in EU-27, Romania, Hungary and Bulgaria. In 2012, recycling rate in Romania was still below the rate of Bulgaria or that of EU-27. However, it has a clear positive trend in 2005-2012 period, minimising the gap between Romania and EU regarding packaging waste management.

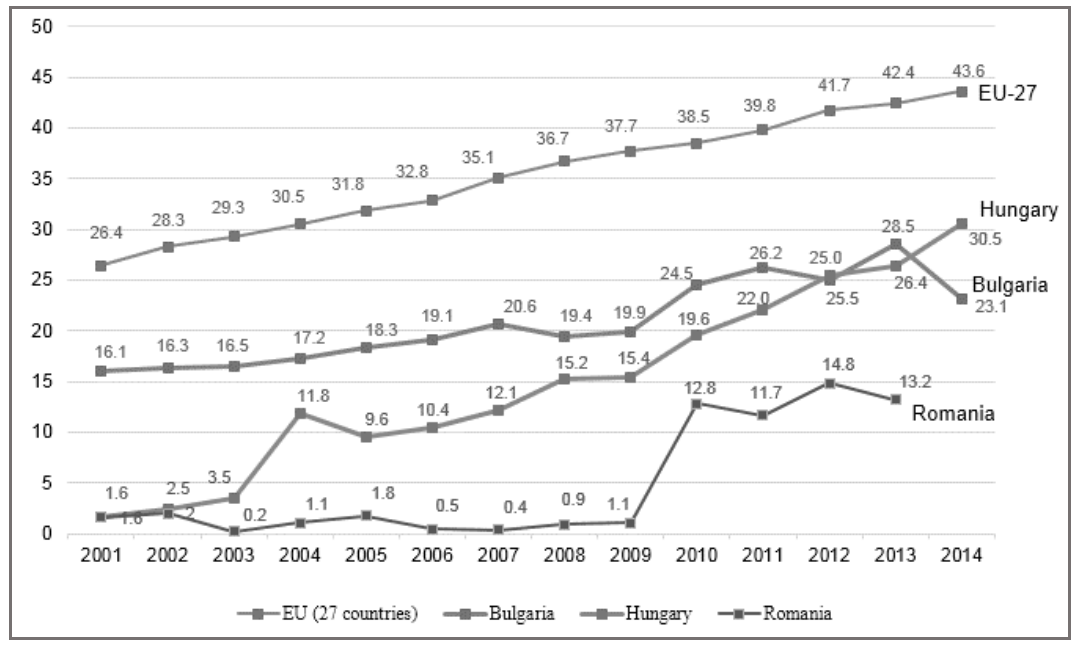

Figure 3-2.Recycling rates for municipal waste in EU-27, Romania, Bulgaria and Hungary, 2001$2014(\%)$

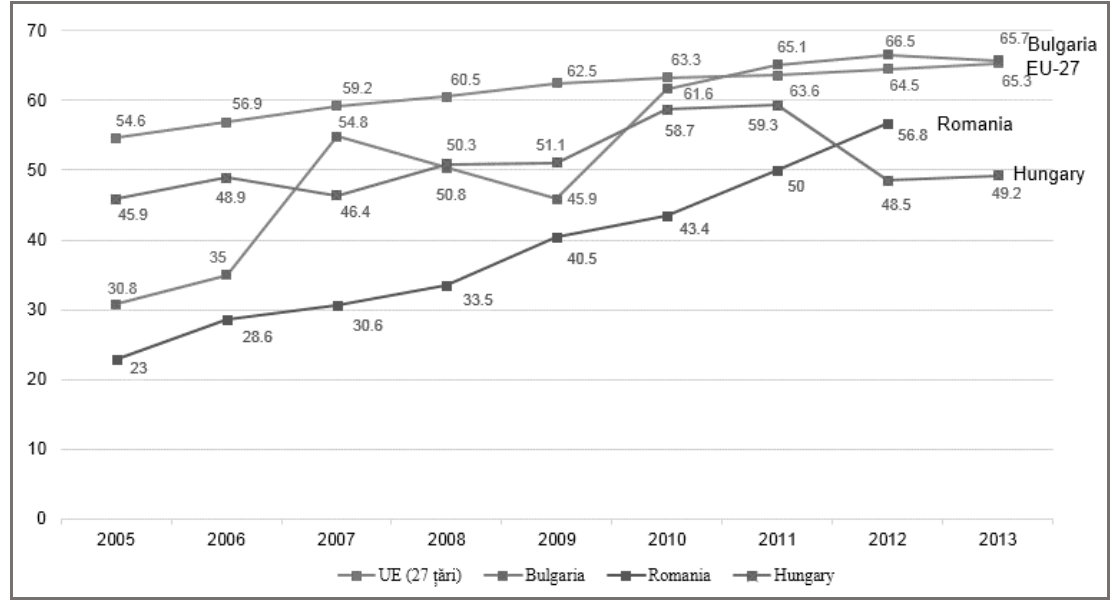

Figure 3-3.Recycling rates for packaging waste- EU-27, Romania, Bulgaria and Hungary, 2005$2013(\%)$

The following graphs present the recycling rates for packaging waste, by type of packaging, for Romania and EU-27, between 2005 and 2012. 


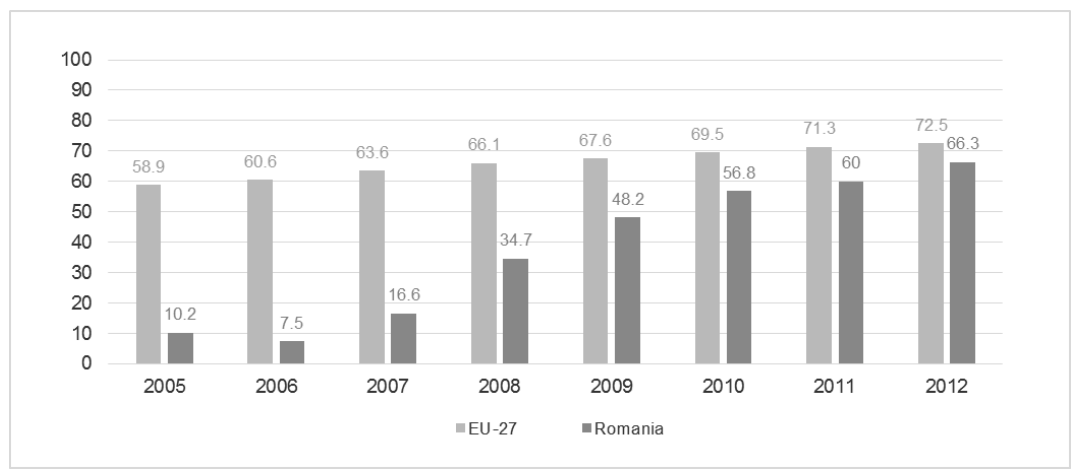

Figure 3-4. Recycling rates for glass packaging waste (\%)

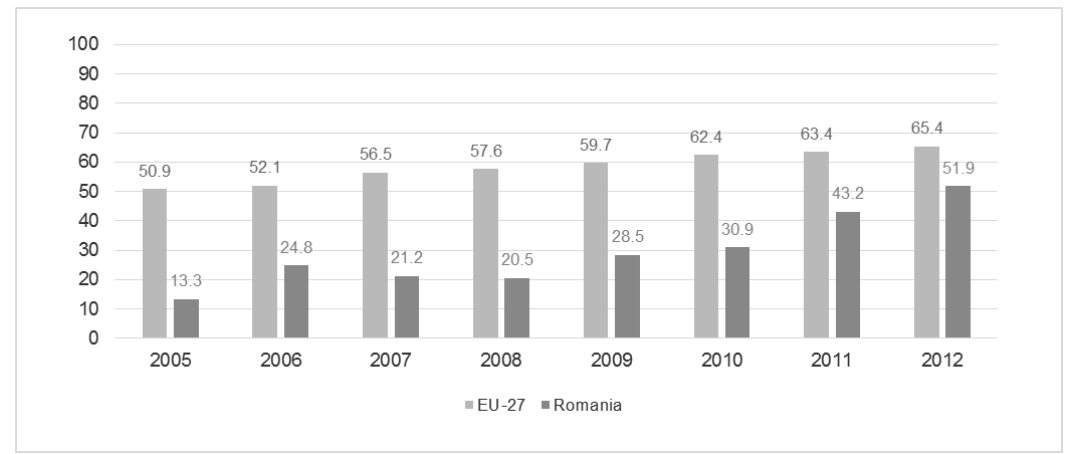

Figure 3-5. Recycling rates for plastic packaging waste (\%)

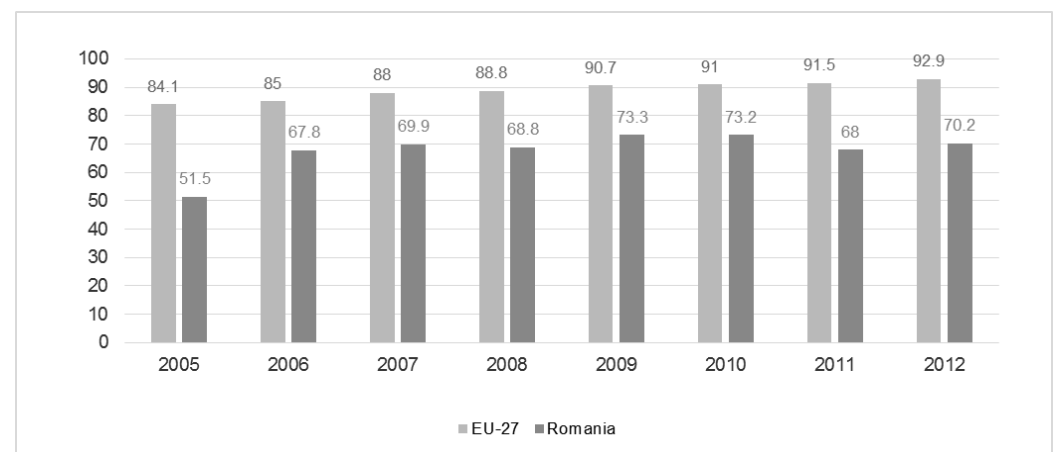

Figure 3-6. Recycling rates for paper and cardboard packaging waste (\%)

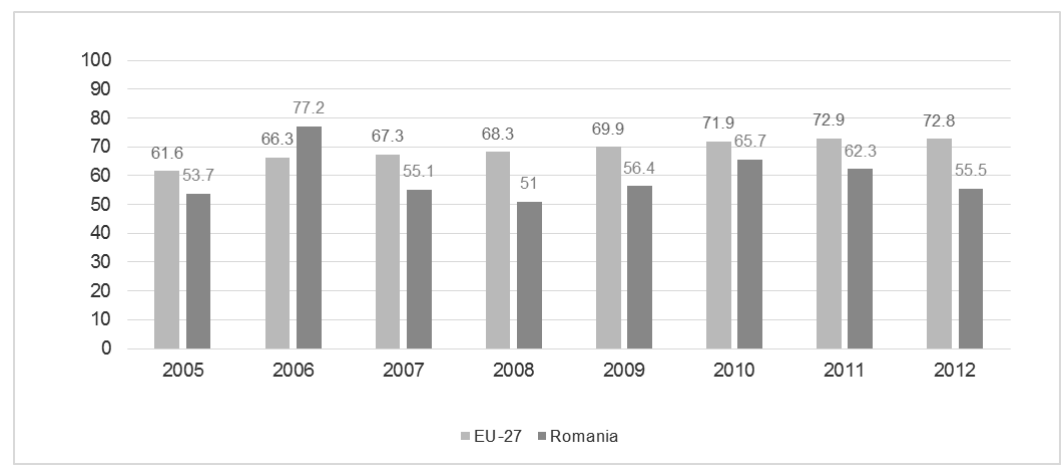

Figure 3-7. Recycling rates for metal packaging waste (\%) 


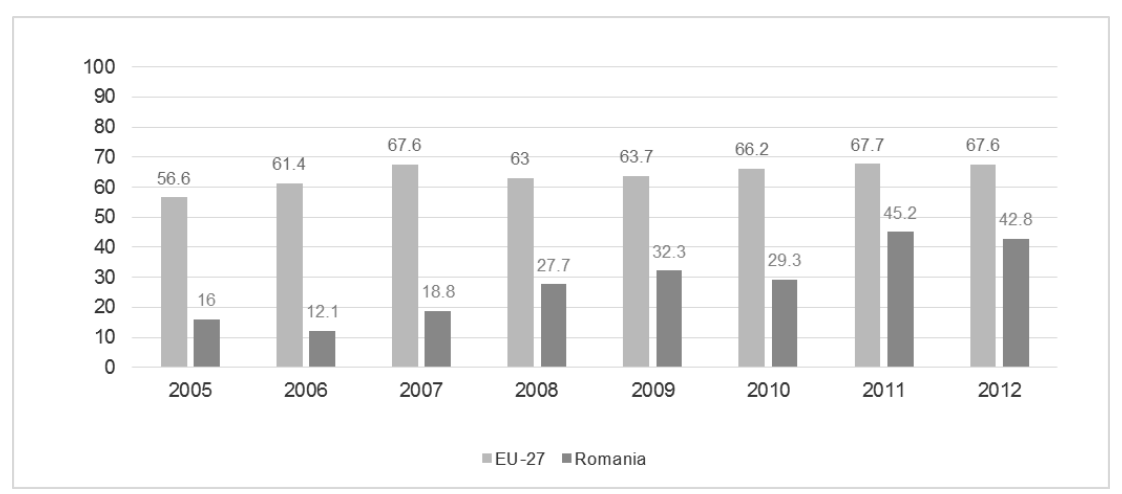

Figure 3-8. Recycling rates for wooden packaging waste (\%)

The recycling rate for glass packaging waste is on a positive trend both for EU-27 and Romania, with a more accelerated growth for Romania, according to Figure 3-4.

The growth of recycling rate of plastic packaging is essential for transition towards circular economy. As shown in Figure 3-5, there is a clear positive trend for plastic packaging recycling rate both in EU and Romania, with a rate of $65.4 \%$ for EU and $51.9 \%$ for Romania, in 2012.

In Figure 3-6, the differences between Romania and EU-27 are higher, regarding recycling rates for paper and cardboard packaging waste. In the case of EU, the rate had a slow, yet constant growth between 2005 and 2012, while in case of Romania, the rate fluctuated around $68 \%$. Recycling the paper and cardboard is very important, since one tonne of recycled paper saves three tonnes of wood. Similarly, the recycling rate for metal package waste had a fluctuating trend for Romania, as shown in Figure 3-7, with a decreasing rate for $2010-2012$, reaching $55.5 \%$ in 2012. In the EU-27, the $72.8 \%$ of the metal package waste was recycled in 2012.

For wooden packaging waste recycling rate, presented in Figure 3-8, the gap between Romania and EU-27 is higher, of around $25 \%$, with a growing rate for Romania, and a stagnant one for EU. In 2012, for example, in the EU, $67.6 \%$ of wooden packaging waste was recycled, while only $42.8 \%$ had the same treatment in Romania.

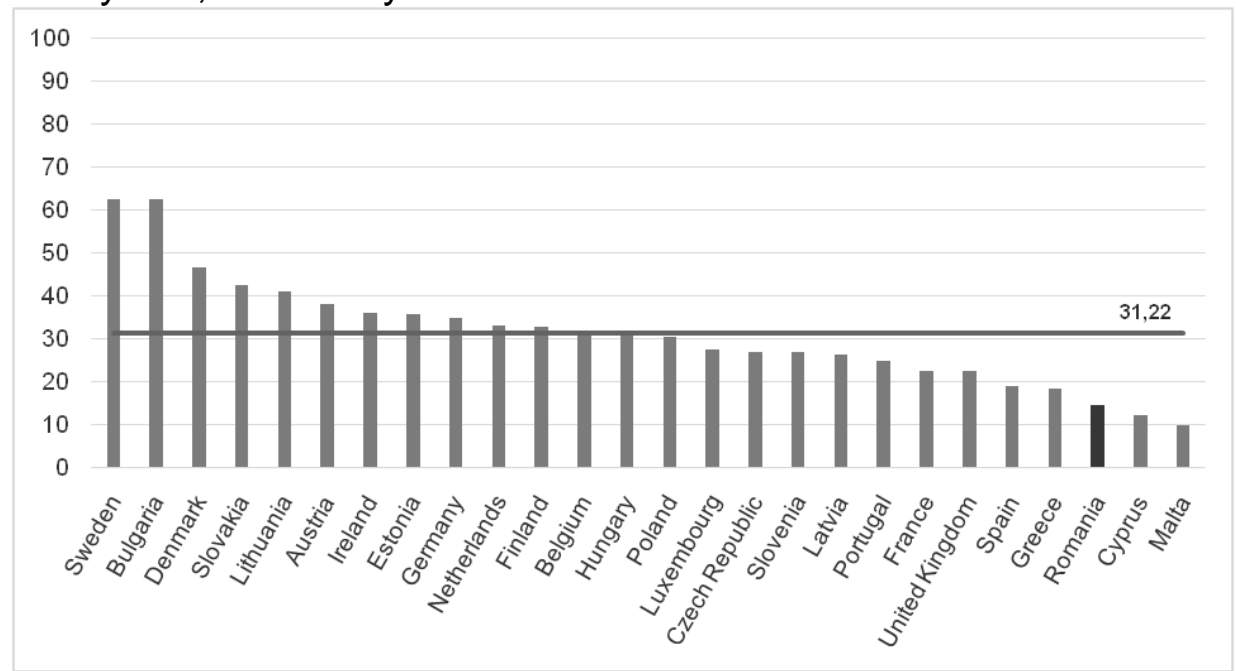

Figure 3-9. Recycling rate of e-waste, in EU countries, in 2012 (\%)

Synthesizing the results for the five types of packaging waste, in 2012, the highest gaps between Romania and EU-27 were recorded for paper and cardboard packaging, wooden packaging and metal packaging waste. Paper and cardboard packaging waste 
has the highest recycling rate, both in EU-27 and Romania, while the lowest rate is that of plastic packaging waste in the EU-27 and wooden packaging waste in Romania. Increasing the capitalization of critical raw materials is one of the challenges to be addressed in the transition to a more circular economy. Figure 3-9 presents the ranking of EU countries based on their e-waste recycling rate. Italy was excluded because of data unavailability. Sweden is leading with a $64.9 \%$ rate, while the EU-27 average is $31.2 \%$. Most of the countries are below the average, and Romania has a recycling rate of only $14.5 \%$, ranking $24^{\text {th }}$ in 26 countries.

\section{Conclusions}

The transition to a circular economy is just at the beginning, and even if the benefits are obvious, it has to face several important barriers, such as the lack of collection schemes and industrial infrastructure for products reuse, lack of value networks and alternative business models, lack of businesses confidence in the operation of a circular model, and lack of demand for circular products.

Companies consider that the biggest challenge is represented by conflict issues related to regulation, collaboration, governance, supply chain dynamics, data transparency, and culture. They do not feel confident about shifting to circular models because of accounting, financial incentives, marketing, and value creation aspects. The solution for overcoming these obstacles resides in linking circular economy with business basis, by making it meaningful to daily operations of a company. Also, servitisation in production, meaning value-added services provided with products, can increase the awareness of businesses. Circular economy requires innovation, which can be improved by stimulating new skills, mainly in STEM subjects (Science, Technology, Engineering, and Mathematics).

Governments should also play an important role, by harmonizing regional policies, developing new policies, applying market incentives to stimulate waste reduction and by supporting alternative business models. However, one of the strongest tools to help implementing circular economy would be a mentality shift for companies and customers, carried out through education. There will be a shift from producer and seller to collaborator and supplier, from consumer to user, and from owner to co-owner.

Regarding waste management, certainly, there is place for improvement at EU level and also in Romania. The main obstacles for improvements are the weak administrative capacity, lack of investments in specific infrastructure, underutilisation of economic instruments and illegal transports of waste (especially hazardous waste, and e-waste).

General solutions include implementing waste management systems, and collection and sorting systems partly funded through schemes of extended producer responsibility, where manufacturers contribute to the cost of collection and treatment of products, applying measures to encourage recycling or applying penalties for noncompliance.

Also, charging storage of waste in landfill sites or applying payment schemes depending on waste generated, taxation of waste generation could reduce the total volume of waste generated. When waste production cannot be prevented or when waste cannot be recycled, energy recovery from waste is a better solution, preferable to storage in landfills.

In conclusion, circular economy will not only enable companies to access new sources of value, but will also help them to create strong markets and supply chains capable of generating long-term prosperity while protecting non-renewable natural resources and reducing environmental pollution. It remains to be seen whether society will understand 
the benefits of circular economy and will accept changing mentalities and the shift from linear economy, driven by property, to circular economy, driven by creating value by use, not by consumption.

\section{Acknowledgements}

The present work benefited form the input of Vladimir Rojanschi, PhD Professor, from Ecological University of Bucharest, who provided valuable ideas and assistance to the writing of the research summarised here.

\section{References}

[1],[3],[5] Ellen MacArthur Foundation (2013), Towards circular economy. Economic and business rationale for an accelerated transition, https://www.ellenmacarthurfoundation.org/assets/downloads/publications/Ellen-MacArthurFoundation-Towards-the-Circular-Economy-vol.1.pdf

[2] European Commission (2015), The Circular Economy Connecting, creating and conserving value, http://www.eesc.europa.eu/resources/docs/the-circular-economy.pdf

[4] The European Files (2015), Circular Economy in Europe. Towards a new economic model. Growth within: A Circular economy. Vision for a competitive Europe, http://europeanfiles.eu/wp-content/uploads/issues/2015-september-38.pdf

[6] European Commission (2014): Scoping study to identify potential circular economy actions, priority sectors, material flows and value chains, p.iv-vi, Report, http://www.ieep.eu/assets/1410/Circular_economy_scoping_study_-_Final_report.pdf

[7] European Environment Agency, Report No 2/2016, Circular Economy in Europe Developing the knowledge base, http://www.eea.europa.eu/publications/circular-economy-ineurope

[8] EPRS (2015), Understanding waste streams. Treatment of specific waste, Briefing,

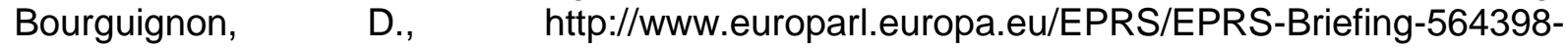
Understanding-waste-streams-FINAL.pdf

[9] UNEP (2009), Developing Integrated Solid Waste Management Plan Training Manual, Volume 4: ISWM Plan,

http://www.unep.org/ietc/Portals/136/Publications/Waste\%20Management/ISWMPlan_Vol4.p df

[10] http://ec.europa.eu/eurostat 